\title{
The Mitigating Effect of Citrullus colocynthis (L.) Fruit Extract against Genotoxicity Induced by Cyclophosphamide in Mice Bone Marrow Cells
}

\author{
Mohammad Shokrzadeh, ${ }^{1,2}$ Aroona Chabra, ${ }^{3}$ \\ Farshad Naghshvar, ${ }^{4}$ and Amirhossein Ahmadi ${ }^{1}$ \\ ${ }^{1}$ Pharmaceutical Sciences Research Center, Faculty of Pharmacy, Mazandaran University of Medical Sciences, \\ 18 Kilometer of Farah Abad Road, Sari, Iran \\ ${ }^{2}$ Department of Toxicology and Pharmacology, Faculty of Pharmacy, Mazandaran University of Medical Sciences, Sari 48175-861, Iran \\ ${ }^{3}$ Student Research Committee, Faculty of Pharmacy, Mazandaran University of Medical Sciences, Sari 48175-861, Iran \\ ${ }^{4}$ Department of Pathology, Faculty of Medicine, Mazandaran University of Medical Sciences, Sari 48175-861, Iran
}

Correspondence should be addressed to Amirhossein Ahmadi; amirhossein_pharma@yahoo.com

Received 11 August 2013; Accepted 24 September 2013

Academic Editors: S. Satar and D. N. Tripathi

Copyright @ 2013 Mohammad Shokrzadeh et al. This is an open access article distributed under the Creative Commons Attribution License, which permits unrestricted use, distribution, and reproduction in any medium, provided the original work is properly cited.

Possible genoprotective effect of Citrullus colocynthis (L.) (CCT) fruits extract against cyclophosphamide- (CP-)induced DNA damage in mice bone marrow cells was evaluated using micronucleus assay, as an index of induced chromosomal damage. Mice were preadministered with different doses of CCT via intraperitoneal injection for 7 consecutive days followed by injection with CP $(70 \mathrm{mg} / \mathrm{kg}$ b.w.) $1 \mathrm{hr}$ after the last injection of CCT. After $24 \mathrm{hr}$, mice were scarified to evaluate the frequency of micronucleated polychromatic erythrocytes (MnPCEs). In addition, the number of polychromatic erythrocytes (PCEs) among 1000 normochromatic erythrocytes (NCEs) per animal was recorded to evaluate bone marrow. Pretreatment with CCT significantly reduced the number of MnPCEs induced by CP in bone marrow cells $(P<0.0001)$. At $200 \mathrm{mg} / \mathrm{kg}$, CCT had a maximum chemoprotective effect and reduced the number of MnPCEs by 6.37-fold and completely normalized the mitotic activity. CCT also led to marked proliferation and hypercellularity of immature myeloid elements after mice were treated with CP and mitigated the bone marrow suppression. Our study revealed that CCT has an antigenotoxic effect against CP-induced oxidative DNA damage in mice. Therefore, it could be used concomitantly as a supplement to protect people undergoing chemotherapy.

\section{Introduction}

Conventional cancer treatments have many modalities, all directed at killing tumor cells or preventing their proliferation. Cyclophosphamide (CP) is an alkylating agent and the most commonly used anticancer and chemotherapeutic drug. Its cytotoxic effects are the result of chemically reactive metabolites that alkylate DNA and protein, by producing cross-links [1]. Immunosuppression and normal tissue injury are the major limitations of chemotherapy [2], which give rise to numerous side effects $[3,4]$. It has been reported that oxidative stress mediated disruption of redox balance after CP exposure generates biochemical and physiological disruptances. $\mathrm{CP}$ is a well-known mutagen and clastogenic agent [5] and produces the highly active carbonium ion, which reacts with the electron-rich area of nucleic acids and proteins [6]. CP is widely used as a genotoxic agent because it and its metabolites can bind DNA, causing damage that may result in chromosome breaks, micronucleus $(\mathrm{Mn})$ formation, and cell death $[6,7]$.

Several studies suggest that antioxidant supplementation can influence the response to chemotherapy as well as the development of adverse side effects that result from treatment with antineoplastic agents [8]. Compounds that could reduce these side effects, as well as stimulate immunity, will be of great help in improving cancer treatment strategies. Recently there is an increasing interest in the search of potential compounds of plant origin that are capable of minimizing 
the toxicity induced by chemotherapy to normal cells without compromising its antineoplastic activity [9]. Natural products exerted protective effects against genotoxicity induced by $\mathrm{CP}$ in bone marrow cells of mice when these compounds were administrated prior to CP treatment. Antioxidant activity is the proposed mechanism for the chemoprotective effects of these natural products $[10,11]$. We previously reported that hesperidin, a citrus bioflavonoid, may have antioxidative activity and can reduce the genotoxicity induced by $\mathrm{CP}$ in mouse bone marrow cells by decreasing micronucleus formation [10]. In addition, an antioxidative herbal medicine with high amount of flavonoids and phenolic compounds had a potent chemoprotective effect against CP-induced oxidative stress and DNA damage in mice bone marrow cells [11]. Therefore, plants with antioxidant activity can be a good source in this regard.

Citrullus colocynthis (L.) (CCT) is one of the native plants of the Middle East countries used in traditional medicine. CCT Schrad., Cucurbitaceae (colocynth or wild-gourd or bitter-apple), is a nonhardy, herbaceous perennial vine, branched from the base. In south-eastern of Iran, CCT locally known as Abujahl watermelon is a well recognized plant in the traditional medicine and was used by people in rural areas as a purgative, antidiabetic, and insecticide. Moreover, traditional medicine in Iran has for centuries used the fruits of CCT for the treatment of diabetes and hemorrhoids [12]. CCT contains active substances such as saponins, alkaloids, and glycosides, and it is used as antidiabetic and antioxidant $[13,14]$. The aqueous extract of the CCT can ameliorate the toxic effect of streptozotocin (STZ) in the liver [15]. The plant extract may be acting as an antioxidant, which clears the reactive oxygen species (ROS) released by STZ since it has been shown that STZ induces ROS and other cytokines [16].

Because CCT has antioxidative properties, there is a likely possibility that CCT would protect against CP-induced DNA damage. Therefore, this study was undertaken to assess the effects of CCT against the genotoxicity induced by CP in mice bone marrow cells using the Mn test. In addition, the biochemical alterations characteristic of CP-induced oxidative stress markers have been measured by use of standard techniques. Histological examination of bone marrow was also used for observation of possible mitigating effect of CCT extract against myelosuppressive effect of CP and bone marrow suppression.

\section{Materials and Methods}

2.1. Plant Material. The fruits of CCT were collected from a local grocery store of Sari city, northern Iran. The plant was identified, authenticated by Dr. Bahman Eslami, assistant professor of plant systematics and ecology, Department of Biology, Islamic Azad University, Branch of Ghaemshahr, Iran.

2.2. Preparation of Extracts. The fruits were dried and the pulps were separated from the seeds. The pulps with peel were pulverized and then powdered in grinding mill. $110 \mathrm{~g}$ of powder was macerated in $1000 \mathrm{~mL}$ of ethanol (70\%) for 72 hours. Following filtration by sterile gauze, the extract was dried after evaporating the ethanol under vacuum at a temperature of $40^{\circ} \mathrm{C}$. The remained water extract was dried at oven temperature of $50^{\circ} \mathrm{C}$. In doing so, $10 \mathrm{~g}$ of hydroalcoholic dried extract powder was obtained.

2.3. Animals. The protocol for the study was approved by the Research Committee of Mazandaran University of Medical Sciences, Sari, Iran. Male Naval Medical Research Institute (NMRI) mice weighing $22 \pm 3 \mathrm{~g}$ were obtained from the Pasteur Institute of Iran (Amol). Before any experience, all animals were maintained 7 days under the same laboratory conditions of temperature $\left(22^{\circ} \mathrm{C} \pm 3^{\circ} \mathrm{C}\right)$, relative humidity $(55 \% \pm 5)$, and a $12: 12$ hours light/dark cycle and received a nutritionally standard diet and tap water ad libitum. The "Care and Use of Laboratory Animals" was prepared by Mazandaran University of Medical Sciences.

2.4. Chemicals. CP (Endoxan) was obtained from Baxter Oncology GMBH (Westfalen, Germany). 1,1-Diphenyl-2picryl hydrazyl radical (DPPH) was purchased from Sigma Chemicals Co. (St. Louis, MO, USA). Butylated hydroxytoluene (BHT) was purchased from Merck (Darmstadt, Germany). Bovine serum albumin and a kit for protein measurement were purchased from Ziest Chem Co. (Tehran, Iran). All other chemicals were either at or purer than analytical grade.

2.5. Measurement of Free Radical-Scavenging Activity of CCT. The free radical-scavenging capacity of CCT was determined by bleaching of the stable DPPH $[17,18]$. Different concentrations of the CCT fruits $(0.5$ to $3 \mathrm{mg} / \mathrm{mL})$ were added, at an equal volume, to a methanol solution of DPPH $(100 \mu \mathrm{M})$. After $15 \mathrm{~min}$ at dark room temperature, the absorbance was recorded at $517 \mathrm{~nm}$. $\mathrm{IC}_{50}$ values denote the concentration of the sample that is required to scavenge $50 \%$ of $\mathrm{DPPH}$ free radicals.

2.6. Experimental Treatment. For the Mn assay, animals were divided into seven groups (Groups $1-7, n=5$ for each group), which were comprised of the following: Group 1 (negative control), mice received distilled water $(10 \mathrm{ml} / \mathrm{kg}$ b.w.) via intraperitoneal (i.p.) injection for 7 days. Group 2 (positive control), mice received a single genotoxic dose of CP (70 mg/kg b.w, i.p.) in distilled water $(10 \mathrm{~mL} / \mathrm{kg} \mathrm{b.w).} \mathrm{Group}$ 3-6, mice were treated with different doses of CCT $(10,50$, 100 , or $200 \mathrm{mg} / \mathrm{kg}$ b.w. by i.p. injection) in distilled water $(10 \mathrm{~mL} / \mathrm{kg}$ b.w) per day for 7 days followed by a single i.p. dose of CP $1 \mathrm{~h}$ after the last dose of CCT. Group 7, mice were treated with only high dose of CCT (200 mg/kg b.w. by i.p. injection) in distilled water $(10 \mathrm{ml} / \mathrm{kg}$ b.w) per day for 7 days.

2.7. Mn Assay. The Mn test was performed as previously described $[10,11]$. The bone marrow Mn test is a well-known in vivo assay for the assessment of genotoxicity and DNA damage in animals such as mice and rats. The number of MnPCEs is increased in rodent bone marrow cells exposed to chemical hazards and chromosome-breaking agents. A Mn is round with a diameter of approximately $1 / 20$ th to $1 / 5$ th of 
an erythrocyte. The ratio of PCE to NCE in bone marrow preparations is useful in estimating any perturbations in hematopoiesis as a result of treatment in exposed animals $[19,20]$.

The femora from the animals were used for estimation of Mn frequency and mitotic activity. Mice were sacrificed by cervical dislocation $24 \mathrm{~h}$ after CP injection. The bone marrow of both femurs was removed in the form of a fine suspension into a centrifuge tube with fetal calf serum (FCS). The cells were dispersed by gentle pipetting and collected by centrifuge at $1500 \mathrm{rpm}$ for $10 \mathrm{~min}$. The cell pellet was resuspended in a drop of FCS, and smears were prepared. The slides were coded to avoid any observed bias. After $48 \mathrm{~h}$ of air drying, smears were stained with May-Grunwald/Giemsa. For each experimental point, five mice were used, and 5000 PCEs were blindly scored microscopically to determine the percentage of MnPCE. In addition, the number of PCEs among 1000 NCEs per animal was recorded to evaluate bone marrow suppression; mitotic activity was calculated as \% PCE = $[\mathrm{PCE} /(\mathrm{PCE}+\mathrm{NCE})] \times 100$ as a direct index of cell division.

2.8. Measurement of Oxidative Stress Markers. To study the effect of CCT extract on oxidative bone marrow damage induced by CP, mice were pretreated with $200 \mathrm{mg} / \mathrm{kg}$ of CCT solution for 7 days followed by injection of CP $(70 \mathrm{mg} / \mathrm{kg}$ b.w.) $1 \mathrm{hr}$ after the last injection of CCT. Femur bonemarrow cells were collected from the mice killed by cervical dislocation $24 \mathrm{hr}$ after CP treatment to estimate lipid peroxidation (MDA), reduced glutathione (GSH), and oxidized glutathione (GSSG) levels.

2.8.1. Determination of Protein Content. The protein content was determined by the method described by Bradford using bovine serum albumin as the standard [21].

2.8.2. Lipid Peroxidation Level. Malondialdehyde (MDA) generated by lipid peroxidation was quantified according to the method of Ohkawa et al. [22], based on thiobarbituric acid reactivity. The MDA concentration in the samples was calculated from the standard curve with 1,1,3,3tetramethoxypropane as the standard and expressed as $\mu \mathrm{mol} / \mathrm{g}$ protein.

2.8.3. Reduced and Oxidized Glutathione Levels. GSH was assayed with DTNB according to the protocol described by Ellman [23]. GSSG was assayed with DTNB, glutathione reductase, and NADPH as described previously [24]. The concentrations of GSH and GSSG were calculated from standard curves that were obtained from freshly prepared standard solutions of GSH and GSSG, respectively, and expressed as $\mu \mathrm{mol} / \mathrm{g}$ protein. The value obtained for GSH was divided by the GSSG value to get the GSH/GSSG ratio.

2.9. Histology of Bone Marrow. For histological examination of myeloid hyperplasia in bone marrow, mice were pretreated with 100 and $200 \mathrm{mg} / \mathrm{kg}$ of CCT solutions for 7 days followed by injection of CP (70 mg/kg b.w.) $1 \mathrm{hr}$ after the last injection of CCT. Both femurs were removed from the mice killed by

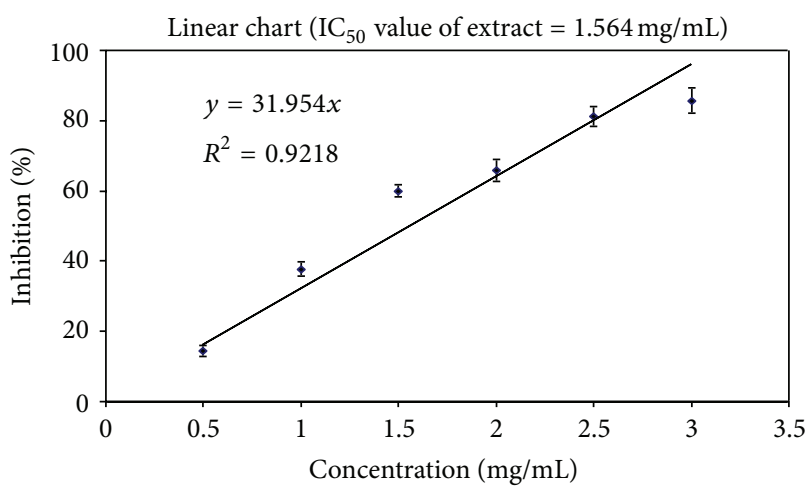

FIGURE 1: Inhibition effect of CCT fruits extract on the DPPH free radical at $517 \mathrm{~nm}$.

cervical dislocation at $24 \mathrm{hr}$ after $\mathrm{CP}$ administration. Femurs were immersed in $10 \%$ formalin; bones were decalcified and processed with a microtome at micron slides. Routine H\&E staining was performed on $6 \mu \mathrm{m}$ paraffin sections, and the slides were evaluated under light microscope. Slides were viewed and photographed using a camera microscope at $400 \mathrm{x}$ magnification.

2.10. Statistical Analysis. Data are presented as the mean \pm SD. One-way analysis of variance and Tukey's honestly significant difference (HSD) test were used for multiple comparisons of data. A $P$ value less than 0.05 was considered to be significant. $\mathrm{IC}_{50}$ values were calculated from linear regression analyses. All measurements were replicated three times.

\section{Results}

3.1. Antioxidant Activity of Extract. The scavenging effect of CCT fruit extract was enhanced with increasing concentration. The maximum inhibitory effects were obtained in $95.862 \%$ at a concentration of $3 \mathrm{mg} / \mathrm{ml}$ for it. The $\mathrm{IC}_{50}$ value of the extract for DPPH radical-scavenging activity was $1.564 \mathrm{mg} / \mathrm{mL}$ (Figure 1).

3.2. Bone Marrow Mn Assay. The effect of various doses of CCT fruits extract on the frequency of MnPCEs in bone marrow cells $24 \mathrm{hr}$ after CP injection is shown in Table 1. The frequency of micronuclei was significantly increased in the mice treated with CP compared with the control group $(P<0.0001)$. In mice pretreated with the CCT at the doses of 100 and $200 \mathrm{mg} / \mathrm{kg}$, the frequency of MnPCEs induced by $\mathrm{CP}$ was significantly decreased compared with those treated with only CP $(P<0.0001)$. The frequency of MnPCEs was lower in the CCT + CP groups by factors of 5.9 and 6.67 for the doses of 100 and $200 \mathrm{mg} / \mathrm{kg}$, respectively, compared with the CP treated group. The data showed that CCT suppresses the action of CP on clastogenic effects. Moreover, the mitotic activity (\% PCE) in CP treated mice showed a pronounced cytotoxic effect of CP on bone marrow proliferation, and this was significantly reduced in mice bone marrow after $\mathrm{CP}$ treatment $(P<0.0001)$. Treatment of mice with CCT arrested 
TABLE 1: Frequency of MnPCE and mitotic activity (\% PCE) in bone marrow cells of mice treated with CCT fruits extract and/or CP.

\begin{tabular}{lccc}
\hline Group & Treatment & $\%$ MnPCE $^{\mathrm{a}}$ & $\%$ PCE $^{\mathrm{a}}$ \\
\hline 1 & Control & $0.54 \pm 0.08$ & $51.32 \pm 6.21$ \\
2 & CP & $6.14 \pm 0.36^{\mathrm{b}}$ & $32.48 \pm 4.15^{\mathrm{b}}$ \\
3 & CCT $10 \mathrm{mg} / \mathrm{kg}+\mathrm{CP}$ & $5.94 \pm 0.72^{\mathrm{d}}$ & $31.28 \pm 7.85^{\mathrm{d}}$ \\
4 & CCT $50 \mathrm{mg} / \mathrm{kg}+\mathrm{CP}$ & $3.62 \pm 0.81^{\mathrm{f}}$ & $40.62 \pm 5.14^{\mathrm{f}}$ \\
5 & CCT $100 \mathrm{mg} / \mathrm{kg}+\mathrm{CP}$ & $1.04 \pm 0.27^{\mathrm{c}, \mathrm{e}}$ & $48.89 \pm 6.78^{\mathrm{c}, \mathrm{e}}$ \\
6 & CCT $200 \mathrm{mg} / \mathrm{kg}+\mathrm{CP}$ & $0.92 \pm 0.06^{\mathrm{c}, \mathrm{e}}$ & $50.32 \pm 8.01^{\mathrm{c}, \mathrm{e}}$ \\
7 & CCT $200 \mathrm{mg} / \mathrm{kg}$ & $0.47 \pm 0.14^{\mathrm{e}}$ & $51.79 \pm 5.46^{\mathrm{e}}$ \\
\hline
\end{tabular}

CCT: Citrullus colocynthis; CP: cyclophosphamide; MnPCE: micronucleated polychromatic erythrocyte.

${ }^{\mathrm{a}}$ Values are the mean \pm standard deviation for each group of 5 mice. ${ }^{\mathrm{b}} \mathrm{P}<0.0001$ compared to the control; ${ }^{\mathrm{c}} \mathrm{P}<0.0001$ compared with the $\mathrm{CP}$ treated group; ${ }^{\mathrm{f}} P<0.001$ compared with the $\mathrm{CP}$ treated group. ${ }^{\mathrm{d}}$ No significant difference compared to the $\mathrm{CP}$ group. ${ }^{\mathrm{e}}$ No significant difference compared to the control group. The data were analyzed with one-way ANOVA and Tukey's HSD test.

TABLE 2: Levels of MDA, GSH, GSSG, and GSH/GSSG ratio in bone marrow of mice after treatment with CCT (200 mg/kg) and/or CP $(70 \mathrm{mg} / \mathrm{kg})$.

\begin{tabular}{lcccc}
\hline Groups $(\mathrm{mg} / \mathrm{kg})$ & MDA $(\mu \mathrm{mol} / \mathrm{g}$ protein $)$ & GSH $(\mu \mathrm{mol} / \mathrm{g}$ protein $)$ & GSSG $(\mu \mathrm{mol} / \mathrm{g}$ protein $)$ & GSH/GSSG ratio \\
\hline Control & $0.74 \pm 0.17$ & $13.64 \pm 4.36$ & $3.38 \pm 0.43$ & $4.03 \pm 1.07$ \\
CP & $3.07 \pm 0.42^{\mathrm{b}}$ & $3.81 \pm 1.47^{\mathrm{b}}$ & $13.38 \pm 3.76^{\mathrm{b}}$ & $0.28 \pm 0.05^{\mathrm{b}}$ \\
CCT & $0.71 \pm 0.32^{\mathrm{c}}$ & $14.69 \pm 5.16^{\mathrm{c}}$ & $2.97 \pm 0.35^{\mathrm{c}}$ & $4.94 \pm 1.72^{\mathrm{c}}$ \\
CCT + CP & $1.32 \pm 0.24^{\mathrm{d}}$ & $12.37 \pm 3.84^{\mathrm{e}}$ & $6.14 \pm 3.84^{\mathrm{d}}$ & $2.01 \pm 0.63^{\mathrm{d}}$ \\
\hline
\end{tabular}

CCT: Citrullus colocynthis; CP: cyclophosphamide; MDA: lipid peroxidation; GSH: reduced glutathione; GSSG: oxidized glutathione.

${ }^{\mathrm{a}}$ Values are the mean \pm standard deviation for each group of 5 mice. ${ }^{\mathrm{b}} \mathrm{P}<0.0001$ compared to the control. ${ }^{\mathrm{c}}$ No significant difference compared to the control group; ${ }^{\mathrm{d}} P<0.001$ compared with the $\mathrm{CP}$ treated group; ${ }^{\mathrm{e}} P<0.0001$ compared with the $\mathrm{CP}$ treated group.

The data were analyzed with one-way ANOVA and Tukey's HSD test.

the CP-induced decline in the mitotic activity (\% PCE) (Table 1). CCT treatment at the doses of 100 and $200 \mathrm{mg} / \mathrm{kg}$ completely prevented the cytotoxicity induced by $\mathrm{CP}$ in the mice bone marrow and increased mitotic activity (\% PCE) as a result of increasing bone marrow proliferation $(P<0.0001)$. CCT extract did not show any significant protective effect at a dose of $10 \mathrm{mg} / \mathrm{kg}$. CCT alone did not also cause any cytotoxicity and genotoxicity in bone marrow cells at a high dose of $200 \mathrm{mg} / \mathrm{kg}$.

3.3. Bone Marrow Lipid Peroxidation Level. The results of the analysis of bone marrow lipid peroxidation are shown in Table 2. The MDA content in mice treated with CP was significantly increased compared with the control group $(P<0.0001)$. CCT pretreatment significantly inhibited the elevation in MDA formation by $\mathrm{CP}$ and restored to the level of control group.

3.4. Bone Marrow GSSG and GSH Levels. The GSH level observed in CP-treated animals was significantly decreased, together with an increase in GSSG as compared with the control group $(P<0.0001)$ (Table 2$)$. The GSH/GSSG ratio also decreased from $4.03 \pm 1.07$ to $0.28 \pm 0.05$, indicating increased oxidative stress. Animals pretreated with CCT showed a significant increase in GSH level over the CP-treated group to the level significantly different from the level of GSH after treatment with $\mathrm{CP}$ alone $(P<0.0001)$. The GSSG level was also significantly decreased in animals pretreated with CCT compared with the CP-treated group $(P<0.001)$.
Consequently, the GSH/GSSG ratio was increased in CCT pretreated animals and was statistically significantly higher when compared with the $\mathrm{CP}$-treated group $(P<0.001)$.

3.5. Histology of Bone Marrow. Histological examination of the bone marrow showed that administration of CP induced myelosuppressive effects (Figure 2(a)). Administration of 100 and $200 \mathrm{mg} / \mathrm{kg}$ CCT led to marked proliferation and hypercellularity of immature myeloid elements after mice were treated with $\mathrm{CP}$, as well as mitigated bone marrow suppression (Figures 2(b) and 2(c)).

\section{Discussion}

The results from our study show the ability of $\mathrm{CP}$ to induce the formation of micronuclei in PCEs in the bone marrow of mice. The induction of micronuclei is commonly used to assess chromosomal damage [25-27]. There are many reports that hazardous environmental chemicals are capable of inducing genotoxic stress and carcinogenic effects on the mammary gland. These effects are primarily due to the production of free radical species that damage critical macromolecules, such as DNA, to promote chronic diseases including cancer. Although the human body is equipped with self-defense mechanisms, exposure to high levels of dangerous chemicals can lead to mutagenic and carcinogenic events [28]. The cellular and tissues toxicity were observed in the increased therapeutic dose of CP. CP and its metabolites can bind DNA, causing damage that may result in 


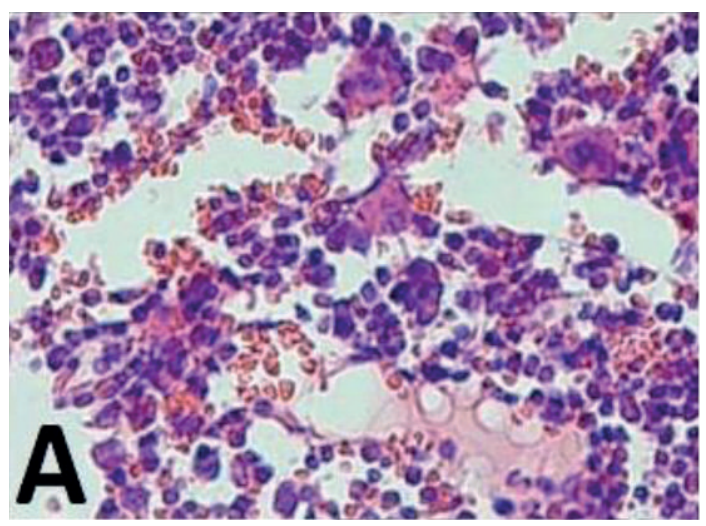

(a)

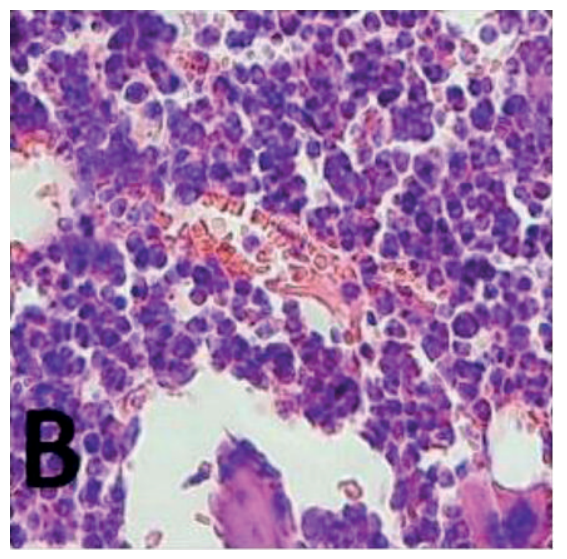

(b)

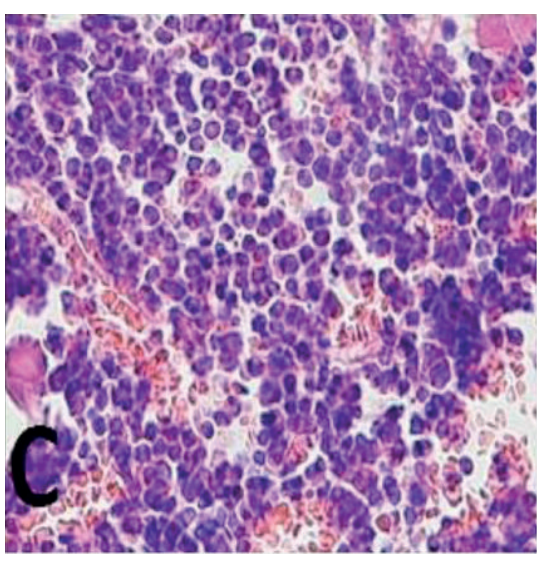

(c)

FIGURE 2: Myeloid hypoplasia in femur 24 hours after CP administration $70 \mathrm{mg} / \mathrm{kg}$; (a) compared with myeloid hyperplasia induced by administration of CCT fruits extract at $100 \mathrm{mg} / \mathrm{kg}$; (b) \& $200 \mathrm{mg} / \mathrm{kg}$; (c) for 7 consecutive days before CP treatment. CP-induced myelosuppressive effects (a) and CCT led to marked proliferation and hypercellularity of immature myeloid elements after mice were treated with $\mathrm{CP}$ and mitigated the bone marrow suppression ((b) and (c)). Note the relative increase in the proportion of myeloid to erythroid precursors after CCT administration (hematoxylin and eosin-stained paraffin sections).

chromosome breaks, micronucleus formation, and cell death $[7,29]$. We previously reported CP-induced oxidative stress and genotoxicity in mice bone marrow cells $[10,11]$. In our recent study, $\mathrm{CP}$ administration induced testicular toxicity and oxidative stress in testis tissues of male mice [30]. The cellular mechanisms by which CP causes testicular injury are poorly understood; however, numerous studies have shown that CP treatment is associated with induction of oxidative stress by the generation of free radicals and ROS [31, 32].

The consumption of vegetables and fruits has been an effective strategy for reducing the genotoxicity and carcinogenicity induced by hazardous chemicals or radiation. The preventive effects of natural products are primarily due to their antioxidant and free radical-scavenging activities [33, 34].

CCT is an important medicinal plant belonging to the family Cucurbitaceae. Several active chemical constituents of CCT plant were recorded. A number of secondary metabolites have previously been reported in this plant including cucurbitacins, flavonoids, caffeic acid derivatives, and terpenoids in addition to flavone glycosides and cucurbitacin glucosides $[35,36]$. CCT also contains flavonoids such as quercetin, myricetin, and kaempferol [37]. In our study, the CCT extract scavenged the DPPH free radical in a dose-dependent manner. The maximum antioxidant activity was observed at a concentration of $3 \mathrm{mg} / \mathrm{mL}$ that inhibited 95.862\% of DPPH free radical (Figure 1), which is totally in agreement with previous studies. In Kumar et al. study, free radical-scavenging effect of CCT fruit extract increased with increasing concentration, and maximum antioxidant activity was observed at $2.5 \mathrm{mg} / \mathrm{mL}$ with the percentage inhibition of $88.0 \pm 2.7$ [38]. Delazar et al. isolated and identified three types of flavonoid, flavone glucosides, and two cucurbitacin glucosides from the methanol extract of the endemic Iranian species CCT fruits. The antioxidant property of these flavonoids was determined by the DPPH assay and showed significant antioxidant properties [35]. We previously reported that medicinal plants and natural products such as flavonoids and phenolic compounds with antioxidant properties and free radical-scavenging mechanism reduced genotoxicity and micronucleus formation in human blood lymphocytes when administrated prior to genotoxic agents 
[39-42]. We recently reported that $O$. vulgare pretreatment attenuated radiation-induced oxidative stress and the subsequent DNA damage in human blood lymphocyte. The protective effect of $O$. vulgare on DNA could be explained by its ability to increase activity of antioxidant defense system, scavenge the ROS that induce lipid peroxidation as well as peroxidative damage, and quench free radicals induced by internal radiation [33].

$\mathrm{CP}$ is a well-known bifunctional alkylating agent widely used in cancer chemotherapy and expresses its genotoxicity when metabolically activated $[43,44]$. Normal tissues injury or damage is the major limitation of using $\mathrm{CP}$, which gives rise to numerous side effects; CP treatment also results in the production of ROS, which cause peroxidative damage to vital organs [45]. CP and its metabolites can bind DNA, causing damage that may result in chromosome breaks, Mn formation, and cell death [7, 29]. Medicinal plants have potential preventive properties because of chemical constituents such as phenolic compounds and flavonoids. The biological benefits of these compounds are generally thought to be a result of their antioxidant and free radicalscavenging properties [28]. In a previous study, administration of CCT increased the activity of antioxidant enzymes defense system in liver and kidney of diabetic rats and helped to control the free radical, as the plant is known to be rich in flavonoids and triterpenoids, well-known antioxidants which scavenge the free radicals generated during diabetes [46]. Cucurbitacins, triterpenoid steroids, are one of the major constituents in CCT. Cucurbitacins are efficient antioxidants, and this property lies in their ability to scavenge free radicals such as hydroxyl radical, superoxide anions, and singlet oxygen. Reports also show that cucurbitacins adequately inhibit lipid peroxidation and oxidation [47]. The results of previous studies suggested that CCT contains a free radicalscavenging activity, which could exert a beneficial action against pathological alterations caused by the presence of free radicals and ROS in degenerative diseases [46]. Since ROS are important contributors to tissue injury, inflammation, cancer, and many other ailments, the antioxidant property of compounds probably contributes to the pharmacological and traditional medicinal uses of the CCT [35].

Hence, we evaluated the chemoprotective effects of CCT fruits extract against genotoxicity induced by $\mathrm{CP}$ in mouse bone marrow for the first time. CCT extract had dose-dependent protective effects, reduced the frequency of MnPCE induced by CP, and increased proliferation of bone marrow cellularity that was affected by CP. Administration of 100 and $200 \mathrm{mg} / \mathrm{kg}$ of CCT to mice prior to the injection of CP reduced the frequency of MnPCE approximately 3.88and 6.37-fold, respectively. CCT treatment also attenuated the bone marrow suppression, which declined in mice treated with CP. Our study also documented a significant rise in the level of MDA in CP only treated group. This rise in bone marrow MDA levels is a consequence of increased lipid peroxidation. MDA, the product of lipid peroxidation, can interact with DNA, causing strand breaks that in turn develop into chromosomal breaks [48]. CCT showed antilipid peroxidation activity which significantly decreased the levels of
MDA. This decrease in lipid peroxidation by CCT might be due to the scavenging of free radicals and ROS. Moreover, CP has a prooxidant nature, and production of oxidative stress after CP administration leads to decrease in the activities of antioxidant enzymes in different tissues of mice and rats $[49,50]$. This can induce genotoxicity through the failure of the antioxidant defense mechanisms. Cellular GSH plays an important role in the antioxidant defense system. The ratio of intracellular GSH/GSSG is also often used as an indicator of the cellular redox state, the degree of oxidative stress, and the antioxidant capacity of cells [51]. We demonstrated that CCT pretreatment reduced the CP-induced oxidative stress and increased the GSH/GSSG ratio significantly. The increased GSH and GSH/GSSG level suggests that protection by CCT may be mediated through the modulation of cellular antioxidant levels. These results are in agreement with other studies. Previously, CCT pulp extract possessed a potent antioxidant property against oxidative stress in the RBC's of alloxan induced diabetic rats. Chronic oral administration of CCT pulp extract restored the altered levels of the enzymatic components of the antioxidant system to their normal levels [52].

\section{Conclusion}

Our study provides evidence that CCT pretreatment attenuates $\mathrm{CP}$-induced oxidative stress and the subsequent DNA damage in mice. CCT had potentially protective and anticlastogenic effect against the genotoxicity and Mn formation induced by $\mathrm{CP}$ in mice bone marrow cells. Histological examination of bone marrow also showed that CCT extract mitigates myelosuppressive effect of $\mathrm{CP}$ and bone marrow suppression. The protective effect of CCT on DNA could be explained by its ability to increase activity of antioxidant defense system, scavenge the ROS that induce lipid peroxidation as well as peroxidative damage, and quench free radicals that induce DNA strand breaks. Therefore, CCT is a good candidate to help defend the body against side effects, particularly genotoxicity of CP-induced oxidative stress condition during chemotherapy.

\section{Conflict of Interests}

The authors declare no conflict of interests.

\section{Acknowledgment}

This study was supported by a grant from the Student Research Committee, Mazandaran University of Medical Sciences, Sari, Iran.

\section{References}

[1] C. Dollery, Therapeutic Drugs, Churchill Livingstone, Edinburgh, UK, 1999.

[2] E. M. Hersh and E. Freireich, "Host defense mechanisms and their modification by cancer chemotherapy," in Methods in Cancer Research, H. Busch, Ed., pp. 355-451, Academic Press, New York, NY, USA, 1968. 
[3] R. M. Bukowski, "The need for cytoprotection," European Journal of Cancer A, vol. 32, no. 4, pp. S2-S4, 1996.

[4] L. H. Fraiser, S. Kanekal, and J. P. Kehrer, "Cyclophosphamide toxicity: characterising and avoiding the problem," Drugs, vol. 42, no. 5, pp. 781-795, 1991.

[5] G. R. Mohn and J. Ellenberger, "Genetic effects of cyclophosphamide, ifosfamide and trofosfamide," Mutation Research, vol. 32, no. 3-4, pp. 331-360, 1976.

[6] E. L. Schneider, H. Sternberg, and R. R. Tice, "In vivo analysis of cellular replication," Proceedings of the National Academy of Sciences of the United States of America, vol. 74, no. 5, pp. 20412044, 1977.

[7] F. R. Moore, G. A. Urda, G. Krishna, and J. C. Theiss, "An in vivo/in vitro method for assessing micronucleus and chromosome aberration induction in rat bone marrow and spleen. 1. Studies with cyclophosphamide," Mutation Research, vol. 335, no. 2, pp. 191-199, 1995.

[8] P. Chakraborty, U. H. Sk, N. Jayanta, K. Das, S. Pal, and S. Bhattacharya, "Modulation of cyclophosphamide-induced cellular toxicity by diphenylmethyl selenocyanate in vivo, an enzymatic study," Journal of Cancer Molecules, vol. 4, no. 6, pp. 183-189, 2009.

[9] P. Pratheeshkumar and G. Kuttan, "Ameliorative action of Vernonia cinerea L. on cyclophosphamide-induced immunosuppression and oxidative stress in mice," Inflammopharmacology, vol. 18, no. 4, pp. 197-207, 2010.

[10] A. Ahmadi, S. J. Hosseinimehr, F. Naghshvar, E. Hajir, and M. Ghahremani, "Chemoprotective effects of hesperidin against genotoxicity induced by cyclophosphamide in mice bone marrow cells," Archives of Pharmacal Research, vol. 31, no. 6, pp. 794797, 2008.

[11] S. J. Hosseinimehr, S. Ahmadashrafi, F. Naghshvar, A. Ahmadi, S. Ehasnalavi, and M. Tanha, "Chemoprotective effects of zataria multiflora against genotoxicity induced by cyclophosphamide in mice bone marrow cells," Integrative Cancer Therapies, vol. 9, no. 2, pp. 219-223, 2010.

[12] N. Sanadgol, S. Najafi, L. V. Ghasemi, G. Motalleb, and A. Afsharimoghadam, "A study of the inhibitory effects of Citrullus colocynthis (CCT) using hydro-alcoholic extract on the expression of cytokines: TNF- $\alpha$ and IL- 6 in high fat diet-fed mice towards a cure for diabetes mellitus," Journal of Pharmacognosy and Phytotherapy, vol. 3, no. 6, pp. 81-88, 2011.

[13] I. A. Abdel-Hassan, J. A. Abdel-Barry, and S. T. Mohammeda, "The hypoglycaemic and antihyperglycaemic effect of Citrullus colocynthis fruit aqueous extract in normal and alloxan diabetic rabbits," Journal of Ethnopharmacology, vol. 71, no. 1-2, pp. 325$330,2000$.

[14] R. Gebhardt, "Antioxidative, antiproliferative and biochemical effects in HepG2 cells of a homeopathic remedy and its constituent plant tinctures tested separately or in combination," Arzneimittel-Forschung, vol. 53, no. 12, pp. 823-830, 2003.

[15] F. Al-Ghaithi, M. R. El-Ridi, E. Adeghate, and M. H. Amiri, "Biochemical effects of Citrullus colocynthis in normal and diabetic rats," Molecular and Cellular Biochemistry, vol. 261, no. 1, pp. 143-149, 2004.

[16] F. Palm, J. Cederberg, P. Hansell, P. Liss, and P. O. Carlsson, "Reactive oxygen species cause diabetes-induced decrease in renal oxygen tension," Diabetologia, vol. 46, no. 8, pp. 1153-1160, 2003.

[17] A. Ahmadi, M. A. Ebrahimzadeh, S. Ahmad-Ashrafi, M. Karami, M. R. Mahdavi, and S. S. S. Saravi, "Hepatoprotective, antinociceptive and antioxidant activities of cimetidine, ranitidine and famotidine as histamine $\mathrm{H}_{2}$ receptor antagonists," Fundamental and Clinical Pharmacology, vol. 25, no. 1, pp. 7279, 2011.

[18] M. Azadbakht, S. J. Hosseinimehr, M. Shokrzadeh, E. Habibi, and A. Ahmadi, "Diospyros lotus L. fruit extract protects G6PDdeficient erythrocytes from hemolytic injury in vitro and in vivo: prevention of favism disorder," European Review for Medical and Pharmacological Sciences, vol. 15, no. 11, pp. 12701281, 2011.

[19] B. B. Gollapudi and L. G. McFadden, "Sample size for the estimation of polychromatic to normochromatic erythrocyte ratio in the bone marrow micronucleus test," Mutation Research Letters, vol. 347, no. 2, pp. 97-99, 1995.

[20] W. Schmid, “The micronucleus test," Mutation Research, vol. 31, no. 1, pp. 9-15, 1975.

[21] M. M. Bradford, "A rapid and sensitive method for the quantitation of microgram quantities of protein utilizing the principle of protein dye binding," Analytical Biochemistry, vol. 72, no. 1-2, pp. 248-254, 1976.

[22] H. Ohkawa, N. Ohishi, and K. Yagi, "Assay for lipid peroxides in animal tissues by thiobarbituric acid reaction," Analytical Biochemistry, vol. 95, no. 2, pp. 351-358, 1979.

[23] G. L. Ellman, “Tissue sulfhydryl groups", Archives of Biochemistry and Biophysics, vol. 82, no. 1, pp. 70-77, 1959.

[24] M. E. Anderson, "Determination of glutathione and glutathione disulfide in biological samples," Methods in Enzymology, vol. 113, pp. 548-555, 1985.

[25] V. Vijayalaxmi, R. J. Reiter, T. S. Herman, and M. L. Meltz, "Melatonin and radioprotection from genetic damage: in vivo/in vitro studies with human volunteers," Mutation Research, vol. 371, no. 3-4, pp. 221-228, 1996.

[26] R. R. Tice, G. L. Erexson, and M. D. Shelby, "The induction of micronucleated polychromatic erythrocytes in mice using single and multiple treatments," Mutation Research, vol. 234, no. 3-4, pp. 187-193, 1990.

[27] J. T. MacGregor, R. Schlegel, W. N. Choy, and C. M. Wehr, "Micronuclei in circulating erythrocytes: a rapid screen for chromosomal damage during routine toxicity testing in mice," in Developments in Science and Practice of Toxicology, A. W. Hayes, R. C. Schnell, and T. S. Miya, Eds., pp. 555-558, Elsevier, Amsterdam, The Netherlands, 1983.

[28] A. K. Tiwari, "Imbalance in antioxidant defence and human diseases: multiple approach of natural antioxidants therapy," Current Science, vol. 81, no. 9, pp. 1179-1187, 2001.

[29] M. Murata, T. Suzuki, K. Midorikawa, S. Oikawa, and S. Kawanishi, "Oxidative DNA damage induced by a hydroperoxide derivative of cyclophosphamide," Free Radical Biology and Medicine, vol. 37, no. 6, pp. 793-802, 2004.

[30] A. Chabra, M. Shokrzadeh, F. Naghshvar, F. Salehi, and A. Ahmadi, "Melatonin ameliorates oxidative stress and reproductive toxicity induced by cyclophosphamide in male mice," Human and Experimental Toxicology, 2013.

[31] U. B. Das, M. Mallick, J. M. Debnath, and D. Ghosh, "Protective effect of ascorbic acid on cyclophosphamide-induced testicular gametogenic and androgenic disorders in male rats," Asian Journal of Andrology, vol. 4, no. 3, pp. 201-207, 2002.

[32] D. Ghosh, U. B. Das, S. Ghosh, M. Mallick, and J. Debnath, "Testicular gametogenic and steroidogenic activities in cyclophosphamide treated rat: a correlative study with testicular oxidative stress," Drug and Chemical Toxicology, vol. 25, no. 3, pp. 281-292, 2002. 
[33] S. Arami, A. Ahmadi, and S. A. Haeri, "The radioprotective effects of Origanum vulgare extract against genotoxicity induced by ${ }^{131}$ I in human blood lymphocyte," Cancer Biotherapy and Radiopharmaceuticals, vol. 28, no. 3, pp. 201-206, 2013.

[34] D. Aune, E. de Stefani, A. Ronco et al., "Fruits, vegetables and the risk of cancer: a multisite case-control study in Uruguay," Asian Pacific Journal of Cancer Prevention, vol. 10, no. 3, pp. 419-428, 2009.

[35] A. Delazar, S. Gibbons, A. R. Kosari et al., "Flavone C-glycosides and cucurbitacin glycosides from Citrullus colocynthis," Daru, vol. 14, no. 3, pp. 109-114, 2006.

[36] C. Seger, S. Sturm, M. Mair, E. P. Ellmerer, and H. Stuppner, ${ }^{11} \mathrm{H}$ and ${ }^{13} \mathrm{C}$ NMR signal assignment of cucurbitacin derivatives from Citrullus colocynthis (L.) Schrader and Ecballium elaterium L. (Cucurbitaceae)," Magnetic Resonance in Chemistry, vol. 43, no. 6, pp. 489-491, 2005.

[37] C. Y. O. Chen and B. Jeffrey, Are There Age-Related Changes in Flavonoid Bioavailability? Phytochemicals Aging and Health, Taylor \& Francis, New York, NY, USA, 2008.

[38] S. Kumar, D. Kumar, M. Jusha, K. Saroha, N. Singh, and B. Vashishta, "Antioxidant and free radical scavenging potential of Citrullus colocynthis (L.) Schrad. methanolic fruit extract," Acta Pharmaceutica, vol. 58, no. 2, pp. 215-221, 2008.

[39] S. J. Hosseinimehr, A. Ahmadi, D. Beiki, E. Habibi, and A. Mahmoudzadeh, "Protective effects of hesperidin against genotoxicity induced by $99 \mathrm{mTc}-\mathrm{MIBI}$ in human cultured lymphocyte cells," Nuclear Medicine and Biology, vol. 36, no. 7, pp. 863-867, 2009.

[40] S. J. Hosseinimehr, A. Ahmadi, A. Mahmoudzadeh, and S. Mohamadifar, "Radioprotective effects of daflon against genotoxicity induced by $\gamma$ irradiation in human cultured lymphocytes," Environmental and Molecular Mutagenesis, vol. 50, no. 9, pp. 749-752, 2009.

[41] S. J. Hosseinimehr, A. Mahmoudzadeh, A. Ahmadi, S. A. Ashrafi, N. Shafaghati, and N. Hedayati, "The radioprotective effect of Zataria multiflora against genotoxicity induced by $\gamma$ irradiation in human blood lymphocytes," Cancer Biotherapy and Radiopharmaceuticals, vol. 26, no. 3, pp. 325-329, 2011.

[42] S. J. Hosseinimehr, A. Mahmoudzadeh, A. Ahmadi, S. Mohamadifar, and S. Akhlaghpoor, "Radioprotective effects of hesperidin against genotoxicity induced by $\gamma$-irradiation in human lymphocytes," Mutagenesis, vol. 24, no. 3, pp. 233-235, 2009.

[43] F. Baumann and R. Preiss, "Cyclophosphamide and related anticancer drugs," Journal of Chromatography B, vol. 764, no. 1-2, pp. 173-192, 2001.

[44] R. A. Fleming, "An overview of cyclophosphamide and ifosfamide pharmacology," Pharmacotherapy, vol. 17, no. 5, pp. 146S-154S, 1997.

[45] J. M. Patel, "Stimulation of cyclophosphamide-induced pulmonary microsomal lipid peroxidation by oxygen," Toxicology, vol. 45, no. 1, pp. 79-91, 1987.

[46] K. A. Jeyanthi and A. M. V. Christy, "Antioxidant effect of Citrullus colocynthis on alloxan induced diabetic rats," International Journal of Pharmaceutical and Biological Archive, vol. 2, no. 2, 2011.

[47] S. A. Bernard and O. A. Olayinka, "Search for a novel antioxidant antiinflammatory/analgesic or anti-proliferative drug cucurbitacins hold the ace," Journal of Medicinal Plant Research, vol. 4, no. 25, pp. 2821-2826, 2010.
[48] M. Dallak and I. Bin-Jaliah, "Antioxidant activity of Citrullus colocynthis pulp extract in the RBC's of alloxan-induced diabetic rats," Pakistan Journal of Physiology, vol. 6, pp. 112-122, 2010.

[49] R. Haque, B. Bin-Hafeez, S. Parvez et al., "Aqueous extract of walnut (Juglans regia L.) protects mice against cyclophosphamide-induced biochemical toxicity," Human and Experimental Toxicology, vol. 22, no. 9, pp. 473-480, 2003.

[50] E. Selvakumar, C. Prahalathan, Y. Mythili, and P. Varalakshmi, "Mitigation of oxidative stress in cyclophosphamide-challenged hepatic tissue by DL- $\alpha$-lipoic acid," Molecular and Cellular Biochemistry, vol. 272, no. 1-2, pp. 179-185, 2005.

[51] O. W. Griffith, "Biologic and pharmacologic regulation of mammalian glutathione synthesis," Free Radical Biology and Medicine, vol. 27, no. 9-10, pp. 922-935, 1999.

[52] S. M. Attia, "Influence of resveratrol on oxidative damage in genomic DNA and apoptosis induced by cisplatin," Mutation Research, vol. 741, no. 1-2, pp. 22-31, 2012. 

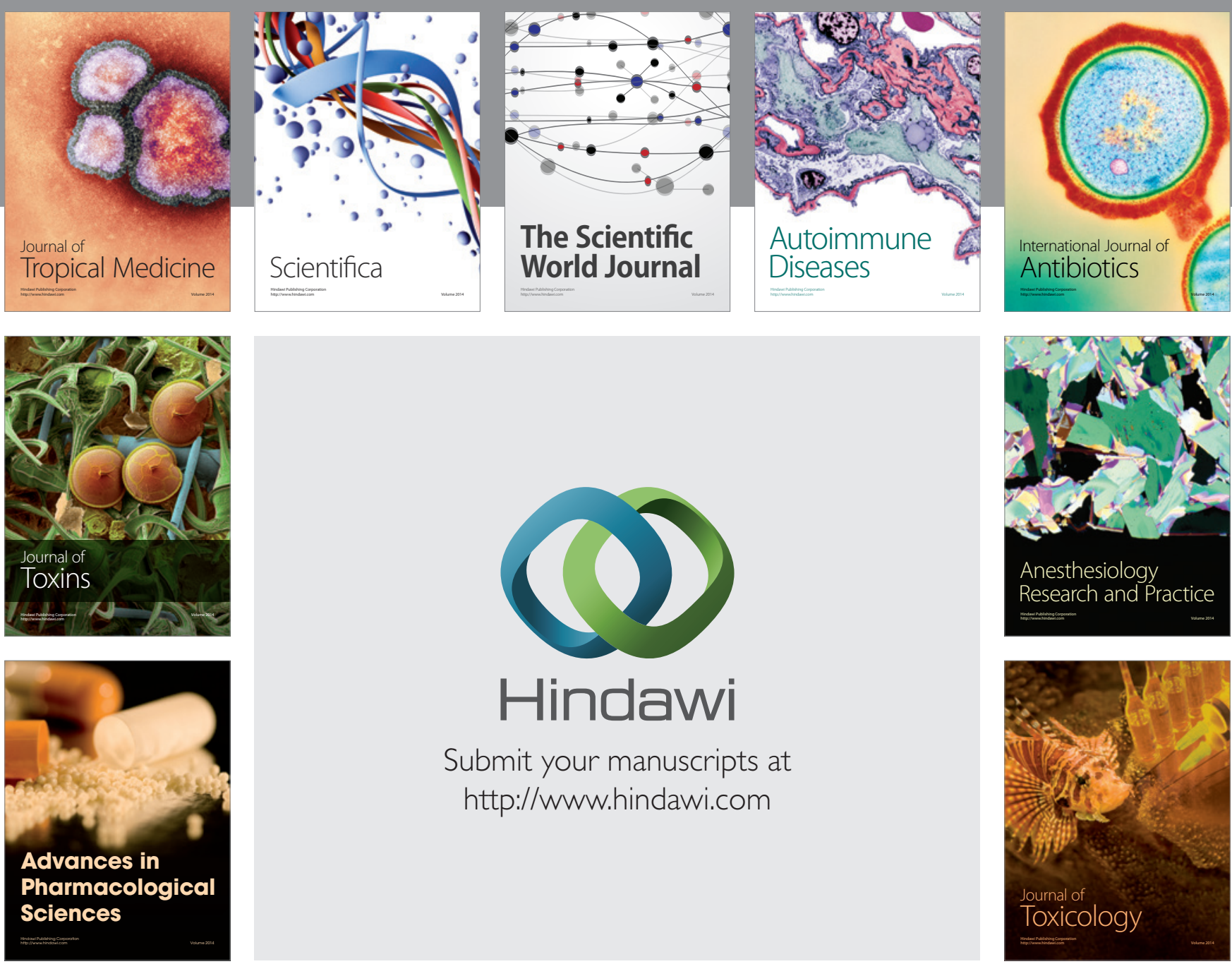

\section{Hindawi}

Submit your manuscripts at

http://www.hindawi.com
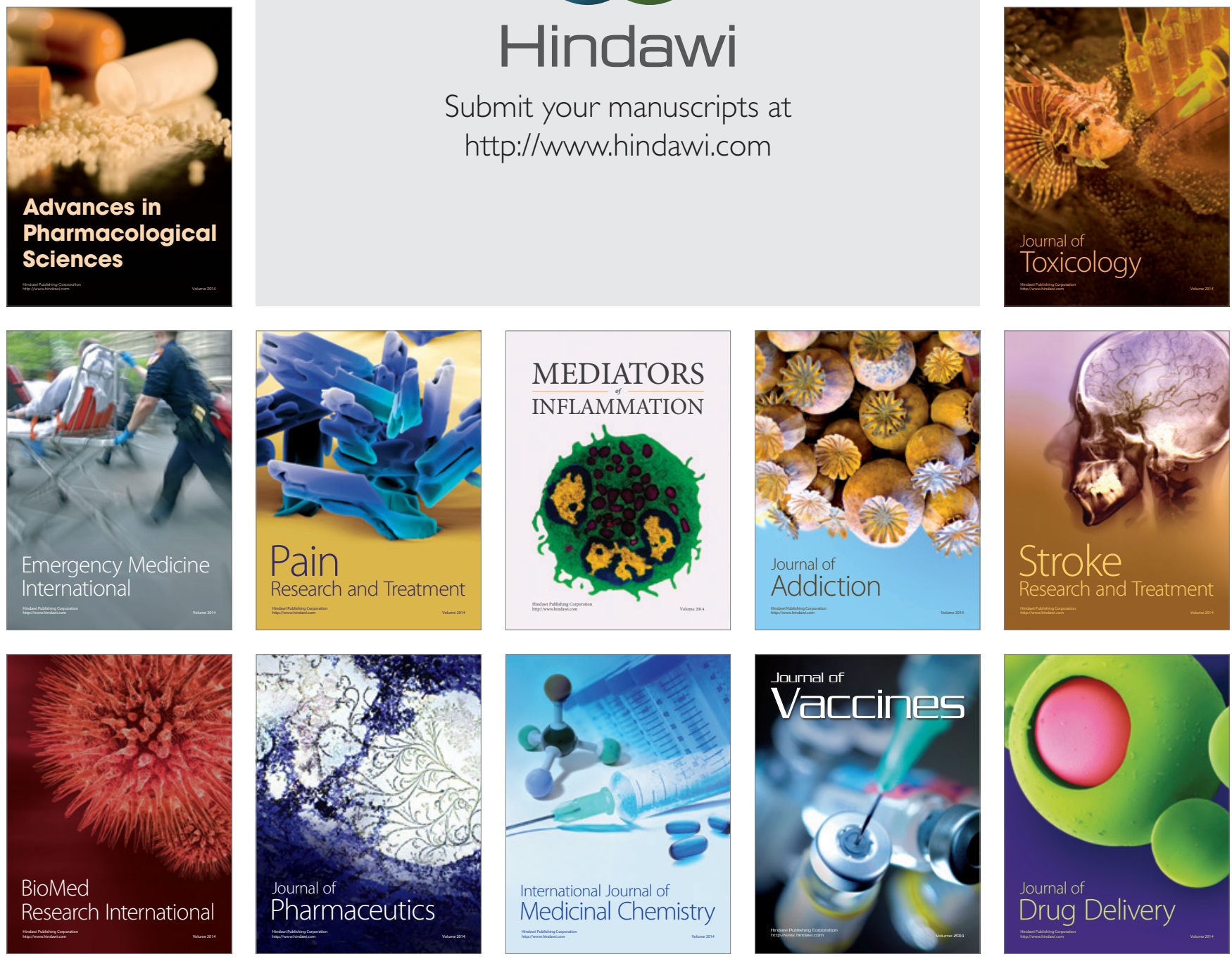